\title{
Store-operated calcium entry in physiology and pathology of mammalian cells
}

\author{
Berenika Targos, Jolanta Barańska and Paweł Pomorski ${ }^{\bowtie}$ \\ Department of Molecular and Cellular Neurobiology, Nencki Institute of Experimental Biology; \\ ${ }_{e-m a i l p p @ n e n c k i . g o v . p l}$
}

Received: 31 January, 2005; revised: 25 February, 2005; accepted: 10 May, 2005

available on-line: 31 May, 2005

\begin{abstract}
One of the numerous calcium-involving processes in mammalian cells is store-operated calcium entry (SOCE) - the process in which depletion of calcium stores in the endoplasmic reticulum (ER) induces calcium influx from the extracellular space. Previously supposed to function only in non-excitable cells, SOCE is now known to play a role also in such excitable cells as neurons, muscles and neuroendocrine cells and is found in many different cell types. SOCE participates not only in processes dependent on ER calcium level but also specifically regulates some important processes such as cAMP production, $\mathrm{T}$ lymphocyte activation or induction of long-term potentiation. Impairment of SOCE can be an element of numerous disorders such as acute pancreatitis, primary immunodeficiency and, since it can take part in apoptosis or cell cycle regulation, SOCE may also be partially responsible for such serious disorders as Alzheimer disease and many types of cancer. Even disturbances in the 'servant' role of maintaining ER calcium level may cause serious effects because they can lead to ER homeostasis disturbance, influencing gene expression, protein synthesis and processing, and the cell cycle.
\end{abstract}

Keywords: calcium signaling, calcium stores, store-operated calcium entry, store-operated channels

Calcium plays a crucial role in many important cellular processes such as gene transcription, cell proliferation and differentiation, apoptosis etc. Signaling pathways are often dependent on changes in free cytosolic calcium level. Calcium ions are also known to regulate enzymes and to interact with a large number of other calcium-binding proteins. There is growing evidence that small disturbances in calcium homeostasis may result in serious dysfunction of fundamental cellular processes and cause several diseases.

There are several mechanisms of calcium activity as a second messenger. The store-operated calcium entry (SOCE) is one of the less studied and described such mechanisms. A reason for such a situation could be the fact that SOCE is a complex process in which depletion of intracellular calcium stores in the endoplasmic reticulum (ER) of non-excitable cells results in calcium influx from extracellular space through store-operated channels (SOCs). Initially SOCE was thought to serve only as a way of replenishing ER calcium stores but soon it was found that the contribution of SOCE to cytoplasmic calcium rises is also important. Intensive studies have revealed that SOCE occurs in many cell types including also some excitable ones and that its disturbances can influence many important processes.

Although during the last decade SOCE has been closely investigated, many questions remain unanswered concerning the molecular identity of SOC channels and the mechanism linking ER depletion to the SOC channels' opening. The present review is an attempt to present the diversity of cellular processes involving SOCE.

Abbreviations: $\mathrm{A} \beta$, amyloid $\beta$; 2-ABP, 2-aminoethyldiphenyl borate; $\mathrm{AC}$, adenylyl cyclase; $\mathrm{APC}$, antigen-presenting cell; $\left[\mathrm{Ca}^{2+}\right]_{\mathrm{i}^{\prime}}$ intracellular calcium concentration; CAI, carboxyamidotriazole; CaMK, calcium/calmodulin-dependent protein kinase; CIF, calcium influx factor; CRAC, calcium release-activated channels; CRE, cAMP-responsive element; CRF, corticotropin-releasing factor; ER, endoplasmic reticulum; FAD, familiar Alzheimer disease; $\mathrm{IP}_{3}$, inositol 1,4,5-trisphosphate; $\mathrm{IP}_{3} \mathrm{Rs}, \mathrm{IP}_{3}$ receptors; JNK, c-Jun- $\mathrm{NH}_{2}$-terminal kinase; LTP, long term potentiation; MLCK, myosin light chain kinase; MMP-2, matrix metalloproteinase 2; NF, neurofibromatosis; NFAT, nuclear factor of activated T cells; PKA, Protein kinase A; PLC, phospholipase C; PM, plasma membrane; PS, presenilin; RBL, Rat basophilic leukemia; RPAECs, rat pulmonary arterial endothelial cells; RPMYECs, rat pulmonary microvascular endothelial cells; SERCA, sarcoplasmic/endoplasmic reticulum calcium transporting ATPase; SOC, store-operated channel; SOCE, store-operated calcium entry; TCR, T-cell receptor; THR, thyrotropin-releasing hormone; TMD, transmembrane domain; TRP, transient receptor protein; VOC, volatge-operated channel. 


\section{MECHANISM OF STORE-OPERATED CALCIUM ENTRY (SOCE)}

In many cells stimulation of plasma membrane receptors evokes a biphasic calcium signal caused by release of calcium stored in the ER and the following calcium influx from the extracellular space, as shown on Fig. 1. Numerous studies have revealed that opening of the calcium channels in the plasma membrane is a result of ER store emptying rather than of the changes in the concentration of free cytoplasmic calcium or inositol 1,4,5-trisphosphate $\left(\mathrm{IP}_{3}\right)$ (Berridge, 1995b). Inhibition of SERCA ATP-ases in the ER by thapsigargin, blocking calcium reuptake into the ER, results in slow ER emptying and can induce SOCE (Thastrup et al., 1989). Since this procedure bypasses the part of the pathway involving phospholipase C (PLC) activation, $\mathrm{IP}_{3}$ activity and opening of the calcium channels in $\mathrm{IP}_{3}$ receptors, thapsigargin is considered one of the best tools for studies on store-operated calcium influx. On this basis the store-operated calcium entry hypothesis was created (Putney, 1990).

SOCE has been found in many cell types but to date it has been studied mostly in non-excitable cells, where it is the main calcium response mechanism. The studies on SOCE are performed using physiological agonists (hormones, neurotransmitters, nucleotides) as well as thapsigargin. To separate the influx phase a special experimental protocol is used, where cells are stimulated in calcium-free medium which allows depleting the ER stores. Such a depletion results in a high but transient peak of cytosolic calcium. When calcium level returns to the basal value, addition of calcium ions to the medium evokes strong calcium influx by the store-operated channels in the plasma membrane (SOCs) reviewed by Parekh and Putney (2005).

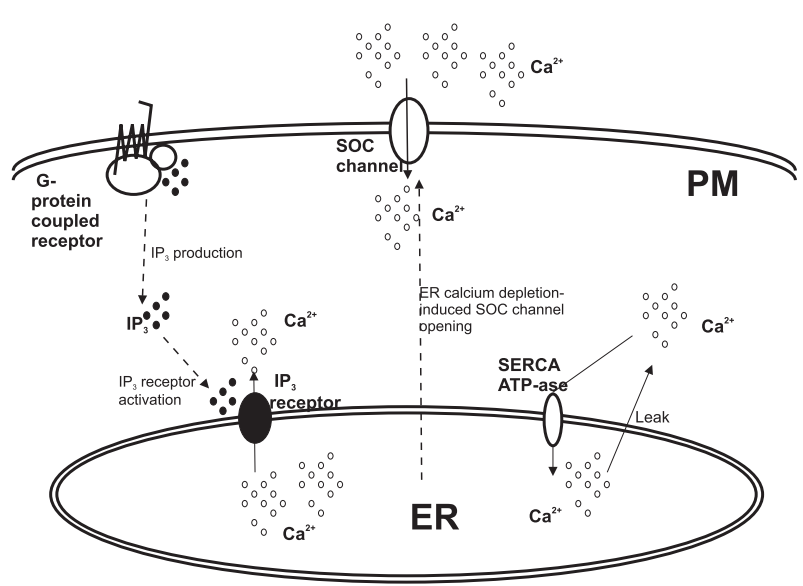

Figure 1. Scheme of store-operated calcium entry.

Activation of plasma membrane receptor coupled with $G$ protein leads to $\mathrm{IP}_{3}$ production which opens calcium channel in $\mathrm{IP}_{3}$ receptor and releases $\mathrm{Ca}^{2+}$ stored in ER. Store depletion activates SOC channel and causes $\mathrm{Ca}^{2+}$ influx from extracellular space. Passive calcium leak from ER is counterbalanced by $\mathrm{Ca}^{2+}$ uptake by SERCA ATP-ases. Similarly to receptor-dependent signal, SERCA inhibition leads to ER depletion which activates SOCE. $\mathrm{Ca}^{2+}$, calcium ions; $\mathrm{ER}$, endoplasmic reticulum; $\mathrm{IP}_{3}$, inositol trisphopsphate; PM, plasma membrane; SERCA, sarco-endoplasmic reticulum calcium ATP-ase; SOC channel, store-operated calcium channel.

Two main unsolved problems concerning SOCE are the molecular identity of SOC channels and the mechanism which links ER depletion with SOC opening. In general, two main models of SOC opening have been proposed - one based on a small diffusible messenger (CIF) released from depleted ER (Randriamampita \& Tsien, 1993), and the second suggesting a direct or indirect physical contact between ER proteins and plasma membrane (Berridge,
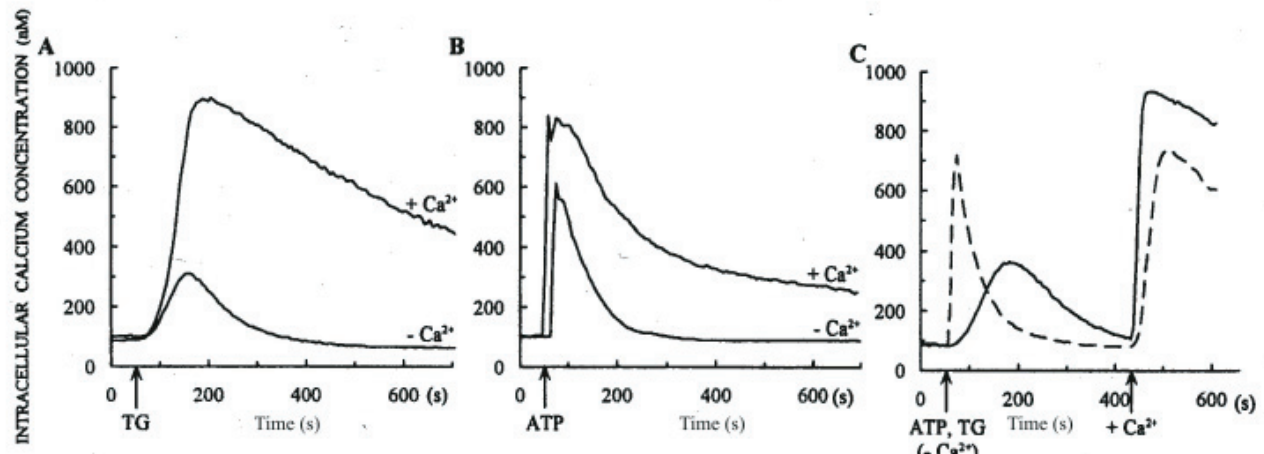

Figure 2. Effect of thapsigargin (TG) and ATP on changes in intracellular $\mathrm{Ca}^{2+}$ concentration in glioma $\mathrm{C} 6$ cells.

(A) Thapsigargin $(100 \mu \mathrm{M})$ was added to cells in standard buffer containing $2 \mathrm{mM} \mathrm{CaCl}$ (upper trace, $+\mathrm{Ca}^{2+}$ ), or no $\mathrm{CaCl}_{2}$ and $500 \mu \mathrm{M}$ EGTA (lower trace; $\left.-\mathrm{Ca}^{2+}\right)$; (B) ATP $(100 \mu \mathrm{M})$ was added to cells in standard buffer containing 2 $\mathrm{mM} \mathrm{CaCl}$ (upper trace, $+\mathrm{Ca}^{2+}$ ), or no $\mathrm{CaCl}_{2}$ and $500 \mu \mathrm{M}$ EGTA (lower trace; $\left.-\mathrm{Ca}^{2+}\right)$; (C) ATP $(100 \mu \mathrm{M})($ dashed line) or thapsigargin $(100 \mathrm{nM})$ (solid line) were added to cells in standard buffer containing no $\mathrm{CaCl}_{2}$ and $500 \mu \mathrm{M}$ EGTA. After 6 min medium was changed for standard buffer containing $2 \mathrm{mM} \mathrm{CaCl}_{2}$. Each trace in $\mathrm{A}, \mathrm{B}$ and $\mathrm{C}$ is mean value for all of cells measured in particular experiment (from: Sabala et al., 1997). 
Table 1. TRP proteins studied as potential candidates for SOC channel elements.

\begin{tabular}{|c|c|c|}
\hline Protein & Function & Properties in different cells \\
\hline TRPC1 & $\begin{array}{l}\text { Probably forming SOC channels with } \\
\text { TRPC3 }\end{array}$ & $\begin{array}{l}\text { Store-operated in } \mathrm{H} 19-7 \text { neurons and in B lymphocytes } \\
\text { Store-operated in CHO, COS, salivary gland cells (heterolo- } \\
\text { gously expressed) }\end{array}$ \\
\hline TRPC2 & $\begin{array}{l}\text { A role in sexual behavior of mice (TRPC2 } \\
\text { knock-outs exhibit sexual behavior deficits) }\end{array}$ & Store operated in COS-M6 cells (heterologously expressed) \\
\hline TRPC3 & $\begin{array}{l}\text { Probably forming SOC channels with } \\
\text { TRPC1, SOC properties only when expres- } \\
\text { sed at low levels }\end{array}$ & $\begin{array}{l}\text { Store-operated in H19-7 neurons } \\
\text { Store-operated in HEK and COS cells (heterologously } \\
\text { expressed) } \\
\text { Not store-operated in bovine arterial cells (heterologously } \\
\text { expressed) }\end{array}$ \\
\hline TRPC4 & $\begin{array}{l}\text { A role in endothelial permeability and va- } \\
\text { sorelaxation }\end{array}$ & $\begin{array}{l}\text { Store-operated in mouse aortic endothelial cells and in bovi- } \\
\text { ne adrenal cortical cells } \\
\text { Not store-operated in proliferating H19-7 neurons and in } \\
\text { HEK cells (heterologously expressed) }\end{array}$ \\
\hline TRPC5 & & $\begin{array}{l}\text { Store-operated when heterologously expressed in HEK cells } \\
\text { - or not (conflicting data) }\end{array}$ \\
\hline TRPC6 & $\begin{array}{l}\text { A role in contractility of tracheal and aortic } \\
\text { smooth muscle }\end{array}$ & \\
\hline TRPC7 & A role in vasorelaxation & Not store-operated in proliferating H19-7 neurons \\
\hline TRPV6 (CaT1) & Involved in prostate cancer progression & $\begin{array}{l}\text { Some properties of SOC in RBL cells } \\
\text { Store-operated in CHO cells (heterologously expressed at } \\
\text { low levels) }\end{array}$ \\
\hline
\end{tabular}

Based on: Minke \& Cook, 2002; Harteneck, 2003; Nilius, 2003; Putney, 2003; Freichel et al., 2004; Nilius, 2004; Wu et al., 2004.

1995b). Many different factors have been shown to modulate capacitative calcium influx, including actin cytoskeleton and some other cytoskeleton-associated proteins, small G proteins, tyrosine kinases and protein kinase C (Baranska et al., 1999; Rosado \& Sage, 2000).

The SOC channels are mostly identified by their properties revealed by patch-clamp experiments which help to discriminate some functional categories but do not give an answer about their molecular identity. Nevertheless, intensive studies on this topic have led to the conclusion that the best group of candidates for SOC channels is the TRP family.

The first TRP protein was found in the Drosophila photoreceptor signaling complex and many more different TRPs have been identified to date, including 28 mammalian homologues. According to their structure these mammalian proteins are classified in groups as TRPC, TRPV, TRPM, TRPP, TRPML and TRPA. Some of these proteins have been shown to be able to form heteromultimeric structures (especially ones from the very well studied TRPC group) and are supposed to form cation channels of different properties.

Studies using numerous molecular methods have revealed that some TRP proteins can form cation channels in vivo and since TRP proteins may form heteromultimers, their properties depend on the pattern and level of expression. It seems clear now that SOC channels formed by TRP proteins do not have the same structure in all cell types but their elements, construction and regulation mechanisms can differ between different cells (Table 1). The function of SOC channels can depend not only on their multimeric construction but also on many additional modulators. It seems that, for example, calmodulin, caveolin, ankyrin, annexin $2, \mathrm{IP}_{3}$ receptors, PLC $\gamma$ and some other proteins can bind to TRPC proteins and probably modify their function, making the whole regulation mechanism more complicated.

\section{SOCE IN DIFFERENT CELL TYPES}

\section{Glioma C6 - a model non-excitable cell}

Among the many types of non-excitable cells glioma C6 seems to be one of the best models for studies on SOCE. It has been shown that these cell belong to the non-excitable cells class, i.e. they do not contain voltage-dependent calcium channels (Baranska et al., 1995). These cells also lack active purinergic P2X ionotropic receptors (Sabala et al., 2001) which makes them a good object for SOCE studies with a clear and undisturbed image of capacitative calcium influx (Baranska et al., 1999).

The shape of the calcium response to ATPstimulation of purinergic metabotropic receptors in glioma C6 cells is characteristically biphasic, with a peak due to calcium release from the ER and a sustained, more prolonged elevation in $\left[\mathrm{Ca}^{2+}\right]_{\mathrm{i}}$ as a result of store-operated influx (Fig. 2). Stimulation with thapsigargin evokes a similar but more prolonged signal (Sabala et al., 1997). In experimental conditions it is possible to separate calcium release 
from the capacitative influx by cell incubation in a calcium-free medium followed by subsequent addition of $\mathrm{Ca}^{2+}$ to the extracellular medium, as described above. Thapsigargin action proves that the calcium influx following ER depletion is store-operated and not activated by the previous rise in cytosolic $\left[\mathrm{Ca}^{2+}\right]_{i}$. Glioma C6 cells proved also to be the perfect model for experimental study of numerous factors influencing SOCE. Figure 3 shows the influence of disorganization of the cell cytoskeleton on calcium transient resulting from the activity of SERCA pump inhibitors (Suplat et al., 2004).

\section{SOCE in lymphocytes}

In contrast to glioma C6 cells, the intracellular calcium stores in lymphocytes - also non-excitable cells - are relatively small and cannot produce a prolonged elevation in cytosolic calcium level (Donnadieu et al., 1994). Hence, the main source for prolongation and amplification of calcium signal is calcium influx from the extracellular space. In lymphocytes it occurs mainly through SOC channels (Lewis, 2001). These thoroughly described channels have been named CRAC and found in many lymphocytic lines (Lewis, 2001). The calcium current conducted by them, called $\mathrm{I}_{\mathrm{CRAC}^{\prime}}$ is one of the best described SOCE currents.

As a main calcium influx pathway, SOCE in lymphocytes can control such cellular events as regulation of transcription factors, organization of the cytoskeleton, cell motility, cytokine production and release as well as cell proliferation (Partiseti et al., 1994; Emptage et al., 2001). SOCE is also necessary for lymphocyte activation (Partiseti et al., 1994; Lewis, 2001). In activated $T$ cells the expression of SOC channels is enhanced and SOCE is significantly augmented. It has been shown that activation of TCR on the cell surface triggers a signaling cascade leading to calcium influx through CRACs (Lewis, 2001). This current provides calcium for sustained cytosolic calcium elevation that is absolutely necessary for interleukin-2 production (Lewis, 2001). Calcium release from intracellular stores cannot induce $\mathrm{T}$ cell activation if not followed by calcium influx. In addition, a role of SOCE in cytotoxicity of T lymphocytes has been suggested (Zweifach, 2000).

Apart from proliferation, activation and motility of lymphocytes there is one more process somehow connected with lymphocytic SOCE-regulated processes: tumor cell defence against the $\mathrm{T}$ cell. It has been shown that stimulation of acid sphingomy-
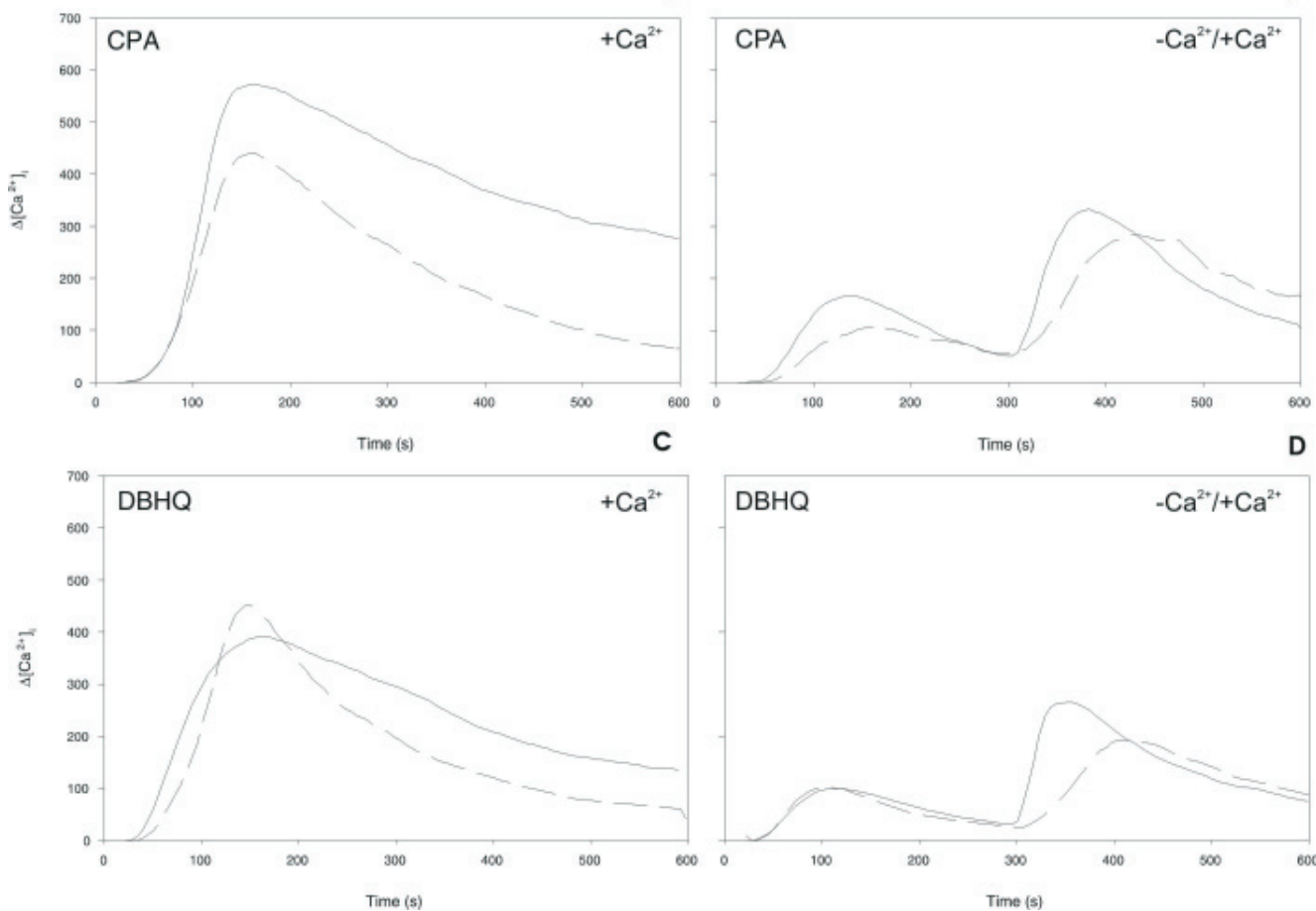

Figure 3. Effect of disorganization of cytoskeleton by cytochalasin D on SERCA ATPase inhibitor induced SOCE.

Two SERCA inhibitors: cyclopiazonic acid (CPA) and 2,5-di-(t-butyl)-1,4-benzohydroquinone (DBHQ) were used, each at $100 \mu \mathrm{M}$. Note that even if disorganization of cytoskeleton has different effect on calcium release from ER, in both cases it weakens SOCE resulting from SERCA pump inhibition (second transient on the right plot) (A) CPA $2 \mathrm{mM} \mathrm{Ca}^{2+}$ environment (B) CPA in calcium free environment (500 $\mathrm{MM}$ EGTA), and then exchange of medium into $2 \mathrm{mM} \mathrm{Ca}^{2+}$ environment (C) DBHQ in $2 \mathrm{mM} \mathrm{Ca}^{2+}$ environment (D) DBHQ in calcium free environment (500 $\mu \mathrm{M} \mathrm{EGTA),} \mathrm{and} \mathrm{then} \mathrm{exchange}$ of medium into $2 \mathrm{mM} \mathrm{Ca}^{2+}$ environment. Solid line: response of control cells, dashed line: response of cells incubated for 1 hour with cytochalasin D (from: Suplat et al., 2004). 
elinase pathway leads to inhibition of SOCE in RBL and $\mathrm{T}$ cells. Thus, it was suggested that sphingolipids produced by cancer cells could play a role of immmunosupressors due to their SOCE-inhibiting action (Lewis, 2001).

Considering the mechanism of SOCE effects, it was suggested that the calcium signal evoked by $\mathrm{T}$ cell activation could act by calcineurin stimulation since some immunosupressors, such as cyclosporine A, are also calcineurin inhibitors (Berridge, 1995a). However, the SOCE-mediated calcium signal in lymphocytes can influence numerous processes depending on the antigen or cell type and maturity (Lewis, 2001). The same stimulus that causes activation of mature $\mathrm{T}$ cells can also cause apoptosis in immature lymphocytes (Blackshaw et al., 2000). The duration and amplitude of calcium signal can precisely regulate different subsets of transcription factors. In HEL-specific naive lymphocytes, where calcium response includes a high peak and a following lower plateau, the first calcium elevation selectively regulates $\mathrm{NF} \kappa \mathrm{B}$ and JNK while activation of NFAT is plateau-dependent (Lewis, 2001). Moreover, each transcription factor depends on a different calcium oscillation frequency (Dolmetsch et al., 1998), hence a single universal second messenger can precisely modulate many different and often opposite processes.

\section{SOCE in excitable cells}

SOCE has also been found in many types of excitable cells and this fact by itself suggests that it should be an important element of calcium homeostasis in these cells and might play a significant role in many processes in the nervous system.

For a long time cells of the nervous system had been thought not to have a store-operated calcium influx pathway. It was obvious that in excitable cells, containing voltage-dependent calcium channels and ionotropic receptors, there is no place for such a pathway of calcium influx. But during the last five years many studies have proved that SOCE occurs also in numerous types of excitable cells (Akbari et al., 2004), including neurons (Emptage et al., 2001). Calcium release from the ER triggering calcium influx through neuronal SOCs may also occur via ryanodine receptors (Emptage et al., 2001). Nevertheless, it seems that the SOCE pathway in excitable cells is an additional but important possibility of regulation of cellular calcium-dependent processes.

Calcium stores' depletion with thapsigargin in dorsal root ganglion neurons is known to inhibit neurite initiation and elongation (Mattson et al., 2000). Since thapsigargin-induced depletion activates also store-dependent $\mathrm{Ca}^{2+}$ influx it cannot be ruled out that also this process is involved in neurite growth regulation. A recent paper reports an in- volvement of SOCE in a taste receptor function (Perez et al., 2003). The involvement of SOCE in longterm potentiation and its role in neurodegenerative disorders will be described in the next parts of this review.

SOCE has also been found in different smooth and skeletal muscle lines (Hopf et al., 1996), where it is supposed to have a real but still unclear physiological role (Kurebayashi \& Ogawa, 2001).

\section{THE ROLE OF SOCE IN A CELL'S LIFE}

\section{Proliferation}

Among the processes in which calcium plays a significant role two opposite determinants of cell life are found: proliferation and apoptosis. Cellular calcium homeostasis is an important factor regulating the switch points of the cell cycle (Whitaker \& Patel, 1990). Particularly the ER calcium homeostasis is crucial for cell growth (Waldron et al., 1997). The abnormal proliferation of some cancer cell lines is connected with strongly elevated $\mathrm{IP}_{3}$ levels and overexpression of PLC which must influence calcium signaling, especially calcium release from the ER stores (Berridge, 1995a). Being connected with the nuclear envelope, ER can relay the changes of calcium balance to the nucleus. As a result, changes of calcium level in the ER and cytosol are closely tied to nuclear calcium homeostasis (Berridge, 1995a). Calcium signal is needed to induce expression of many immediate-early response genes (Roche \& Prentki, 1994), main examples being c-Jun, c-Fos and $C R E$. On entry into mitosis one of the main effectors of the calcium signal is calmodulin and CaMK. Inhibition of these proteins can disturb the cell cycle (Whitaker \& Patel, 1990).

Strong evidence can be found for SOCE importance in calcium signaling regulating the cell division (Golovina et al., 2001). SOCE could mediate cell proliferation by influencing calcium homeostasis in the ER. Inhibition of SOCE could prevent store replenishment which in turn would inhibit cell growth (Short et al., 1993) and proliferation (Gill et al., 1996) probably by influencing gene expression and protein processing. Additionally, disturbances of SOCE could change the pattern of calcium oscillations that is important for gene expression (Enfissi et al., 2004).

The best known examples of SOCE-dependent regulation of proliferation have been found in lymphocytes and several types of cancer cells. Lymphocyte proliferation depends almost exclusively on SOCE, as was shown mostly in the Jurkat T cell line (Lewis, 2001). Proliferation and activation of $\mathrm{T}$ cells correlates with enhanced expression of proteins from the transient receptor proteins family (TRP), namely TRPC and TRPV (Lewis, 2001). This suggests that 
these proteins may be involved in SOC channel formation.

In hepatoma cells the proliferation was correlated with the level of SOCE (Enfissi et al., 2004). LNCaP cancer cells stimulated with EGF present enhanced SOCE and proliferation. Both these processes are attenuated in serum-deprived cells (Vanden Abeele et al., 2003). Noteworthy is that the level of expression of different TRP proteins seems to correlate with cell proliferation, especially for TRPC4 in pulmonary artery endothelial cells (Fantozzi et al., 2003) and TRPC6 in pulmonary artery smooth muscle cells (Yu et al., 2003), where both TRPC types are thought to mediate SOCE. Some SOC blockers, such as CAI and 2-APB, have been shown to inhibit proliferation in hepatoma cells (Enfissi et al., 2004) which raises the possibility that SOCE inhibitors could be used as antiproliferative drugs in cancer therapy.

\section{Apoptosis}

The participation of calcium in apoptotic pathways is undisputed but many of its aspects remain elusive. It is generally accepted that changes in intracellular calcium compartmentalization can induce and regulate apoptosis (Lam et al., 1994; He et al., 1997). There are two general hypotheses about calcium role in apoptosis: the first implies that the main trigger of apoptotic signaling cascades is the depletion of intracellular calcium stores in the endoplasmic reticulum (Lam et al., 1994; He et al., 1997; Pinton et al., 2000; Vanden Abeele et al., 2002). The second hypothesis is based on the role of the prolonged rise of cytosolic calcium level (Berridge, 1995a; Distelhorst \& Dubyak, 1998). In both cases SOCE may be an important part of calcium-involving apoptotic pathways.

In models based on ER depletion SOCE could play a role as one of the sources for the replenishment of calcium stores and have an anti-apoptotic activity. In prostate cancer cells inhibition of SOC channels strongly augmented cell death (Vanden Abeele et al., 2003). Also in osteoclasts inhibition of SOCE resulted in great enhancement of ER depletion-induced apoptosis (Mentaverri et al., 2003).

In the second hypothesis the main trigger for calcium-modulated apoptosis would be sustained elevation of cytosolic calcium level (Wang et al., 1999). Some studies have proved that chelation of cytoplasmatic calcium inhibits apoptosis in prostate cancer cells and thymocytes (He et al., 1997; Wei et al., 1998). Apoptosis of cancer cells caused by irradiation, TGF- $\beta$, doxorubicin or 5 -fluorouracil requires calcium influx by an unknown pathway (Prevarskaya et al., 2004). It has been suggested that some threshold level of cellular calcium must be reached to induce cell death (He et al., 1997).

In $\mathrm{CHO}$ cells incubated without extracellular calcium (which prevents calcium influx) apoptosis was significantly attenuated and authors linked it with a delayed expression of the GADD153 transcription factor (Pigozzi et al., 2004). In hamster embryonic cells apoptosis is preceded by a drop in ER calcium level (Preston et al., 1997) and the authors suggest that the lower calcium pool in the ER may be a result of attenuated SOCE.

A strong correlation between SOCE and apoptosis was found by Jayadev et al. (1999) who described a correlation between SOCE disturbances and impaired secretion. Since it is known that apoptosis is accompanied by secretion disturbances (Wyllie, 1997) these results support the thesis on a significant role of SOCE in apoptosis.

Thus, the data about the role of calcium and SOCE in apoptosis are somehow vague. One of the reasons may be the cellular specificity of some apoptotic pathways and of the calcium involvement in this process. Besides, the anti- or proapoptotic action of the calcium signal may depend on its amplitude and duration (Yu et al., 2001). SOCE itself, acting as the source of calcium for store replenishment, might have a protective role in the normal state of the ER but promote apoptosis in case of any disturbances in ER calcium homeostasis (Pigozzi et al., 2004) or prolonged activity of SOC channels.

Little is known in general about the mechanisms of SOCE-dependent apoptosis, however, some cases have been studied in detail. Among the many effects which may be evoked by a SOCE-related calcium signal during apoptosis is activation of calcineurin which is dependent on sustained cytosolic calcium signal (Jayaraman \& Marks, 2000). Calcineurin causes dephosphorylation of the NFAT transcription factor, its translocation to the nucleus (Timmerman et al., 1996) and activation of NFAT-dependent genes. There is evidence that in lymphocytes dephosphorylation of NFAT is SOCE-dependent and that this process is mediated by calcineurin (Jayaraman \& Marks, 2000). It has been also shown that induction of NFAT-regulated transcription depends on the duration and amplitude of cytosolic calcium rise (Lewis, 2001).

It is also worth to mention that a correlation between high concentration of $\mathrm{IP}_{3}$ receptors $\left(\mathrm{IP}_{3} \mathrm{Rs}\right)$ and apoptosis was found in lymphocytes and prostate cancer cells (Blackshaw et al., 2000; Jayaraman \& Marks, 2000). In this context especially interesting are type $3 \mathrm{IP}_{3} \mathrm{Rs}$, associated with the plasma membrane (Putney, 1990) and participating in regulation of SOC channels (Kiselyov et al., 1999; Blackshaw et al., 2000). Taken together these data suggest that both $\mathrm{IP}_{3} \mathrm{Rs}$ and SOCE are involved in apoptosis reg- 
ulation and that their role may be somehow correlated.

\section{Differentiation}

Besides an involvement in proliferation and apoptosis, there is growing evidence that SOCE can also be linked to cell differentiation. The correlation between proliferation and differentiation of H19-7 neuronal cells and TRPC1 and TRPC3 expression proves that SOCE in neurons may modulate also these important processes. TRPC1 and 3 are known to form at least part of SOC channels not only in H19-7 cells, but also in HEK-293 (Wu et al., 2004). Thus their role in SOCE seems to be well proved. Supression of these' proteins expression with antisense RNA results in diminished SOCE and causes apoptosis instead of differentiation (Wu et al., 2004).

Cell differentiation has been shown to result in changed properties of SOCE and expression of SOC channels. Such a relationship was described for muscle cells (Broad et al., 1996), monocytic line U937 (Floto et al., 1996) and HL60 cells (Gardner et al., 1997). In dendritic cells, where SOCE has been shown to be the main pathway of calcium influx, it promotes cell maturation (Hsu et al., 2001). Similar data were obtained for monocytes and bone marrow cells (Koski et al., 1999).

\section{THE ROLE OF SOCE IN CELL FUNCTION}

\section{Cell shape and motility}

Store-operated calcium influx has been found in many endothelial cells (Luckhoff \& Clapham, 1994; Fasolato \& Nilius, 1998), including vascular and pulmonary endothelium (Chetham et al., 1999; Norwood et al., 2000; Freichel et al., 2004). It was shown that in endothelial cells SOCE was responsible for nitric oxide production and prostaglandin synthesis (Freichel et al., 2004). There is also strong evidence for a crucial role of SOCE in regulation of pulmonary endothelium permeability (Chetham et al., 1999; Norwood et al., 2000). It has been shown that thrombin-induced permeability is connected with ER depletion-activated calcium influx SOCE (Freichel et al., 2004).

Airways endothelial permeability is caused by changes of cell shape and intercellular gap formation (Chetham et al., 1999). Since the shape changes are caused by reorganization of the cytoskeleton and its contractility, the correlation between the cytoskeleton and SOCE was investigated. The hypothesis about an involvement of the cytoskeleton in SOCE regulation (Rosado \& Sage, 2000) was confirmed also for endothelial cells (Norwood et al., 2000). Cytoskeleton tension is mediated by myosin light chain kinase (MLCK) and it was shown that inhibition of MLCK not only promoted reorganization of the cytoskeleton and cell shape changes but also inhibited SOCE. It is possible that cytoskeleton participates in maintaining contact between SOC channels in the plasma membrane and ER (Chetham et al., 1999; Norwood et al., 2000). Nevertheless, there is also the possibility that calcium release from the ER can induce cytoskeleton contractility and cause opening of stretch-activated membrane calcium chanels (Pletjushkina et al., 2001; Pomorski et al., 2004). Such mechanism could co-exist with SOCE and therefore ought to be taken into account.

As described earlier, TRPC4 protein was postulated to be either a part of SOC channel or a SOCE modulator in vascular endothelial cells (Freichel et al., 2004). In mouse microvascular endothelial cells induction of SOCE should stimulate production of nitric oxide and cause vasorelaxation. It was shown that in cells with a knock-out of TRPC4, SOCE was almost completely inhibited and the vasorelaxation induced by agonists was attenuated (Freichel et al., 2004). This leads to the conclusion that TRPC4-mediated SOCE is an important part of the microvascular vasorelaxation mechanism. Moreover, monolayers of knock-out TRPC4 endothelial cells show significantly lower resistance to permeability which again links SOCE impairment with endothelial barrier function (Freichel et al., 2004).

Interestingly, the involvement of SOCE in permeability regulation in endothelial cells seems to be cell type-dependent. Although both in rat pulmonary arterial endothelial cells (RPAECs) and in rat pulmonary microvascular endothelial cells (RPMVECs) the strength of SOCE related calcium transients does not differ, induction of SOCE does not cause a shape change or influence endothelial permeability in RPMVECs (Chetham et al., 1999) while it does so in RPAECs (Chetham et al., 1999; Norwood et al., 2000). These differences may result from different cytoskeleton organization in these cell lines (Chetham et al., 1999).

In the pulmonary circulation SOCE is involved not only in the endothelial function but also regulates agonist- and hypoxia-induced contraction of vascular smooth muscle cells. The main argument is that inhibition of SOCE can block contraction induced by both stimuli in pulmonary aorta cells (Ng \& Gurney, 2001). Potential SOC channels in aorta smooth muscle cells have been described (Trepakova et al., 2001). Since supression of TRP1 was shown to block SOCE (Xu \& Beech, 2001), a role for TRP proteins, i.e. TRPC1 and TRPC3, in SOC channel construction in these cells has been suggested. SOCE involvement in the regulation of vascular smooth muscle contraction makes SOC channels a potentially good target for pulmonary hypertension therapy. 
The cellular shape change induced by SOCE has also been suggested to play a role in angiogenesis (Beck \& D'Amore, 1997). Inhibition of plasma membrane calcium channels in HUVEC endothelial cells blocks cell proliferation, migration and tube formation during angiogenesis (Kohn et al., 1996). Short inhibition of calcium influx by CAI (a nonspecific voltage-independent calcium channel blocker) inhibits cell flattening that is a prerequisite for normal and pathological vase formation. CAI also weakens cell adhesion to the substrate, extracellular matrixstimulated migration and collagenase IV production. A lack of SOCE can also inhibit production of metalloproteinase MMP-2 and attenuate collagenolysis, an important part of angiogenesis and cancer cell invasion (Kohn et al., 1996).

The mechanism of vascular formation is very similar to that of cancer invasion. SOCE inhibition by CAI can stop not only angiogenesis but also cancer cell proliferation and invasion (Kohn et al., 1996). Calcium influx is one of processes involved in cell adhesion to the extracellular matrix induced by integrin crosslinking. Some extracellular matrix proteins, i.e. fibronectin and vitronectin, can induce calcium influx in endothelial cells (Alessandro et al., 1996).

Store-operated calcium influx also takes part in the regulation of $\mathrm{T}$ cell motility. Shortly after contact with the antigen-presenting cell (APC) cloned $\mathrm{T}$ cells present elevation of cytosolic calcium level followed by cell rounding and inhibition of motility (Donnadieu et al., 1994). The same processes can be induced by use of thapsigargin or ionophores. It has been shown that the calcium signal is not needed for the formation of the lymphocyte-APC contact but is necessary to maintain this connection (Delon et al., 1998). Cytosolic calcium elevation induces reorientation of the cortical actin cytoskeleton to the contact region (Wulfing \& Davis, 1998).

An important role of SOCE in the regulation of cell function has also been shown in platelets, where calcium mobilization controls platelet aggregation. It is suggested that impairment of SOCE may be responsible for hyperreactivity of platelets from patients with non-insulin-dependent diabetes mellitus, possibly being a cause of micro- and macroangiopathy in these patients (Saavedra et al., 2004).

\section{Secretion and neurotransmission}

As mentioned above, capacitative calcium influx can also be found in excitable cells. One of its roles in these cells seems to be regulation of neurotransmitter secretion. Recently, it was proved that SOCE regulates spontanic release of neurotransmitters in neurons (Emptage et al., 2001). SOCE is known to take part in regulation of exocytosis in non-excitable cells (Parekh \& Penner, 1997), interneu- rons of hippocampus (Savic \& Sciancalepore, 1998). In bovine chromaffin cells, SOCE is an element of the angiotensin-induced signaling cascade that mediates secretion (Robinson et al., 1992). It is possible that in synaptic boutons in the hippocampus SOCE is also involved in exocytosis regulation (Emptage et al., 2001). Since store-operated calcium influx has been found in hippocampal neurons (Bouron, 2000) also in these cells it may be involved in neurotransmitter release. Moreover, participation of SOCE in synaptic transmission makes it one of the regulators of synaptic plasticity (Emptage et al., 2001).

SOCE may also be involved in regulation of secretion in neuroendocrine cells (Rohacs et al., 1994), but this seems to be species- and cell population-dependent. It is possible that in excitable cells SOCE may be used as an alternative pathway of calcium influx.

SOCE involvement in secretion has also been described in non-excitable cells. A role of SOC channels formed by TRPC4 in calcium regulation of pancreatic $\beta$ cells and in insulin secretion has also been suggested but not proven (Freichel et al., 2004). SOCE is part of calcium influx stimulated by thyrotropin-releasing hormone (TRH) in $\mathrm{GH}_{3}$ pituitary cells and regulates hypophyseal secretion of prolactin (Villalobos \& Garcia-Sancho, 1995). Capacitative calcium influx is also one of the calcium influx pathways in mature placenta and probably is involved in neuropeptide-4-mediated secretion of CRF during pregnancy (Belkacemi et al., 2005).

\section{Crosstalk with adenylyl cyclases}

One of the most interesting examples of SOCE-regulated processes is the very close relation between store-dependent calcium influx and some types of adenylyl cyclase (AC) dependent signaling. Among the many adenylyl cyclases some are negatively regulated by calcium. These calcium-inhibited ones are localized in the plasma membrane and seem to be regulated mostly by calcium influx from the extracellular space (Fagan et al., 2000). AC I, VI and VIII have been shown to be dependent on calcium influx but not on its release from intracellular stores (Cooper et al., 1994; Chiono et al., 1995; Fagan et al., 2000). Moreover, calcium influx stimulated by ionomycin was ineffective in AC regulation (Fagan et al., 2000), which led the authors to a conclusion that SOCE-dependent ACs and SOC channels have to be localized together in PM microdomains. Calcium influx through voltage-gated channels could also regulate ACs but to a lesser extent. This suggests very close colocalization of ACs and SOCs, in contrast to VOCs (Fagan et al., 2000). The lack of an effect of cytoskeleton disruption with cytochalasin D on SOCE-dependent AC regulation seems to prove that colocalization and coupling of ACs and SOCs 
depends rather on lipid segregation or protein-protein interaction than on cytoskeleton structure (Fagan et al., 2000). This relationship is to date the only published example of such an intimate dependence of regulation of a particular protein on SOCE.

\section{SOCE-RELATED DISEASES}

\section{Acute pancreatitis}

An important role has been suggested for SOCE in acute pancreatitis in which premature activation of trypsin precursor stored in secretory granules leads to autodigestion of the pancreas. The enzyme activation has been shown to require prolonged cytosolic calcium elevation while calcium oscillations or short calcium peaks with a high amplitude seem to be insufficient (Parekh, 2000). SOCE was shown to be the source for calcium signal prolongation (Raraty et al., 2000) and SOC channels are considered a good target for acute pancreatitis therapy.

\section{Primary immunodeficiency}

In a disease called primary immunodeficiency, stimulation of TCR receptor cannot cause $\mathrm{T}$ cell activation, the well-documented reason being a lack of functional SOCE (Partiseti et al., 1994). Lymphocytes obtained from patients with primary immunodeficiency have normal calcium stores and present calcium release comparable to the control, but depletion-induced calcium influx is almost absent, probably because of dysfunctional SOC channels or an impaired link between store depletion and SOC opening.

\section{Duchenne's dystrophy}

There is some evidence for SOCE involvement in Duchenne's dystrophy which is connected with changes of calcium homeostasis. Cells obtained from patients with Duchenne's dystrophy present enhanced calcium influx that has been shown to be SOCE (Vandebrouck et al., 2002). In the cell line mdx from a mouse model of dystrophy, suppression of TRPC1 and 4 attenuated SOCE. Having a dystrophin-homology domain (Lockwich et al., 2000), TRPC1 could be dependent on proper cytoskeleton organization and a lack of dystrophin might result in enhanced SOCE that in turn could activate calcium-dependent proteases that have been shown to be overactivated in dystrophic muscle fibers (Vandebrouck et al., 2002). Those findings are also an argument for a physiological role of SOCE in such excitable cells as skeletal muscles.

\section{Neurofibromatosis}

In neurofibromatosis NF1 - a disease which causes bone neoplasms, learning deficits, mental handicap and predispositions to some malignant tumors - significant deficits of SOCE have been described without any apparent changes in ER calcium storage and release (Korkiamaki et al., 2002). Since SOCE has been shown to play an important role in osteoclast survival and apoptosis (Mentaverri et al., 2003) and in LTP induction (Emptage et al., 2001; Ris et al., 2003), it is possible that deficits of SOCE could be responsible for some of the many disorders observed in neurofibromatosis (Korkiamaki et al., 2002).

\section{Neurodegenerative disorders}

Even though Alzheimer disease cannot be considered a calcium homeostasis disorder, SOCE in affected cells usually changes during this illness. Some of familial forms of Alzheimer disease are evidently caused by particular missense mutations in genes coding for presenilins 1 and 2 (PS-1, PS-2), known to be responsible for the processing of amyloid precursor protein. Mutations found in familiar type of Alzheimer disease (FAD) have been shown to cause not only the well described changes in amyloid $\beta(\mathrm{A} \beta)$ production (Akbari et al., 2004) but also to disturb calcium homeostasis (Mattson et al., 2000; Yoo et al., 2000). These specific mutations causing FAD are not equivalent to a lack of PS function - knock-outs of PS do not present Alzheimer disease phenotype (Putney, 2000). The question of the potential role of PS-1 in the regulation of calcium homeostasis is a widely studied one but this mechanism has not been established yet.

Since PS1 is localized mostly in the ER and its mutations may lead to abnormalities of intraluminal calcium homeostasis it has been postulated that the SOCE changes observed in Alzheimer disease are a simple result of disturbed ER calcium storage and release (Smith et al., 2002). Numerous groups have reported enhanced calcium release from the ER (Mattson et al., 2000; Yoo et al., 2000) and lower SOCE in cells with FAD PS1 mutations (Waldron et al., 1997). Taken together these two processes may lead to ER depletion and induce apoptosis (He et al., 1997) as well as influence many other processes dependent on ER calcium level (Meldolesi \& Pozzan, 1998).

This apparently clear picture is somewhat disturbed by the fact that other groups have reported, conversely, enhanced SOCE in cells with FAD PS1 mutations (Yoo et al., 2000). Together with the evidence that in knock-outs of PS1 SOCE is strongly augmented, these findings have led the authors to conclude that the physiological role of PS1 in cal- 
cium regulation is inhibition of SOCE that protects the ER from calcium overload.

Recent results of studies using different PS1 mutants helped to understand the mechanism of PS-1 mutations-related SOCE changes. Akbari et al. (2004) showed that mutations of PS-1 could diminish ER capacity but while point mutation enhanced SOCE, deletion of transmembrane domains caused opposite changes. These findings prove that FAD mutations-related changes in $\gamma$-secretase activity and ER calcium balance are not related to the changes observed in SOCE (Akbari et al., 2004). It also looks like PS-1 regulates SOCE by its transmembrane domains 1 and 2 (TMD1 and TMD2).

Calcium influx is also connected with $\mathrm{A} \beta$ production and its toxicity (Nicotera \& Orrenius, 1998). These connections seem to be somehow related to the cytoskeleton since it has been shown that calcium influx may induce cytoskeleton changes typical for Alzheimer disease. Moreover, depolymerization of the cytoskeleton can inhibit calcium influx and prevent A $\beta$ toxicity (Mattson et al., 2000). Thus, even if Alzheimer disease is not caused by $\mathrm{Ca}^{2+}$ homeostasis impairment, the latter may be responsible for many disease symptoms, e.g. cell death.

At the end it is worth noting that PS-1 mutations result in SOCE changes not only in neurons but also in other cell types, i.e. fibroblasts from patients with Alzheimer disease. This could be useful in early diagnosis of Alzheimer disease (Ito et al., 1994). Given that in cells with FAD PS1 mutations many changes seem to be related to attenuated SOCE, there is a chance that substances stimulating SOC channels could be useful in Alzheimer disease prevention and/or therapy (Yoo et al., 2000).

The role of SOCE in LTP, considered to be one of the mechanisms of memory formation, seems to be linked to the action of presenilin 1 (PS-1). It is worth to mention that in cells without PS-1 calcium influx through SOC channels is sufficient for LTP induction (Ris et al., 2003). The second phase of LTP induction that is dependent on de novo protein synthesis involves a signaling cascade triggered by cAMP-dependent PKA which is activated by strong calcium influx. Probably in cells lacking PS-1 enhanced SOCE is sufficient for this PKA activation. Currently, intensive research concerns the reasons of neurodegenerative disorders and it seems that devoting some attention to SOCE involvement would be worthwhile. Participation of SOCE in LTP regulation may explain many of the memory defects observed in different neurodegenenative disorders. Based on data from Drosophila mutants a theory has been put forward that alterations in expression of TRP forming a SOC channel could be the basis of some neurodegenerative brain diseases (Missiaen et al., 2000).

\section{Cancer}

The role of SOCE in apoptosis and proliferation was discussed above. Both processes are especially important in cell transformation and malignancy. The apoptotic resistance of cancer cells is linked to changes in calcium homeostasis, including calcium influx (Jayadev et al., 1999; Pinton et al., 2000).

Many studies about the role of SOCE in cancer cells were performed on prostate cancer cells, especially on a line from a lymph node metastasis of prostate cancer, LNCaP (Vanden Abeele et al., 2003). This line is androgen independent mainly as a result of its enhanced apoptosis resistance. In androgen-independent cells all the elements involved in apoptosis are present but the triggering mechanism seems not to work (Prevarskaya et al., 2004). It has been suggested that in androgen-dependent cells apoptosis triggered by androgen deprivation is connected with prolonged elevation of cytosolic calcium (Prevarskaya et al., 2004) but the contribution of SOCE in this elevation is not known.

Cancer grade correlates with expression of TRPV6 (Fixemer et al., 2003; Vanden Abeele et al., 2003) that according to many studies may be a component of a SOC channel (Xu \& Beech, 2001). Pharmacological inhibition of androgen receptor enhances expression of TRPV6 and augments SOCE (Vanden Abeele et al., 2003). Antisense suppression of TRPV6 in LNCaP cells attenuates SOCE by about $50 \%$. Also TRPC1, TRPC4 and TRPC6 are investigated as potential SOC forming proteins in prostate cancer cells (Vanden Abeele et al., 2003).

The role of SOCE in cancer cells is controversial. It has been shown that cells that become apoptosis-resistant show enhanced Bcl-2 expression which correlates with attenuated SOCE (Prevarskaya et al., 2004). In such apoptosis-resistant cells depletion of ER calcium stores is not sufficient to trigger apoptosis and the role of SOCE-dependent calcium signal in apoptosis is clearly visible (Vanden Abeele et al., 2002; Vanoverberghe et al., 2004). A lower number of SOC channels has been reported in such cells (Vanden Abeele et al., 2002; Vanoverberghe et al., 2004), consistent with attenuated SOCE but in opposition to some reports about enhanced expression of the channel-forming protein TRPV6 (Prevarskaya et al., 2004).

Despite these discrepancies, the obvious coincidence between TRPV6 expression, its participation in SOCE and the important role of SOCE in proliferation and apoptosis of cancer cells encourages a search for anticancer therapeutics among SOC channels modulators (Vanden Abeele et al., 2003). For example, it seems that the calcium influx inhibitor CAI, a potent inhibitor of cell adhesion, migration, vascular tube formation and multiple minor proc- 
esses involved in angiogenesis, could be one of the best candidates for use in cancer therapy, being able to stop not only proliferation of cancer cells but also invasion and tumor angiogenesis (Kohn et al., 1996).

In conclusion, involvement of SOCE in such crucial processes as those described above makes this phenomenon an important subject of scientific studies, especially in search for the molecular identity of SOC channels. There is hope that these studies will not only solve many problems of SOCE regulation but also may have a practical use in drug targeting and therapy for some diseases.

\section{Acknowledgements}

This review was supported by grants No. 3 P04C 02825 and 3 P04A 01224 from the State Committee for Scientific Research (KBN, Poland).

\section{REFERENCES}

Akbari Y, Hitt BD, Murphy MP, Dagher NN, Tseng BP, Green KN, Golde TE, LaFerla FM (2004) Presenilin regulates capacitative calcium entry dependently and independently of $\gamma$-secretase activity. Biochem Biophys Res Commun 322: 1145-1152.

Alessandro R, Masiero L, Liotta LA, Kohn EC (1996) The role of calcium in the regulation of invasion and angiogenesis. In Vivo 10: 153-160.

Baranska J, Chaban V, Czarny M, Sabala P (1995) Changes in $\mathrm{Ca}^{2+}$ concentration in phorbol ester and thapsigargin treated glioma C6 cells. The role of protein kinase $\mathrm{C}$ in regulation of $\mathrm{Ca}^{2+}$ entry. Cell Calcium 17: 207-215.

Baranska J, Przybylek K, Sabala P (1999) Capacitative calcium entry. Glioma C6 as a model of nonexcitable cells. Pol J Pharmacol 51: 153-162.

Beck L Jr, D'Amore PA (1997) Vascular development: cellular and molecular regulation. FASEB J 11: 365-373.

Belkacemi L, Bedard I, Simoneau L, Lafond J (2005) Calcium channels, transporters and exchangers in placenta: a review. Cell Calcium 37: 1-8.

Berridge MJ (1995a) Calcium signalling and cell proliferation. Bioessays 17: 491-500.

Berridge MJ (1995b) Capacitative calcium entry. Biochem J 312: 1-11.

Blackshaw S, Sawa A, Sharp AH, Ross CA, Snyder SH, Khan AA (2000) Type 3 inositol 1,4,5-trisphosphate receptor modulates cell death. FASEB J 14: 1375-1379.

Bouron A (2000) Activation of a capacitative $\mathrm{Ca}^{2+}$ entry pathway by store depletion in cultured hippocampal neurones. FEBS Lett 470: 269-272.

Broad LM, Powis DA, Taylor CW (1996) Differentiation of BC3H1 smooth muscle cells changes the bivalent cation selectivity of the capacitative $\mathrm{Ca}^{2+}$ entry pathway. Biochem J 316: 759-764.

Chetham PM, Babal P, Bridges JP, Moore TM, Stevens T (1999) Segmental regulation of pulmonary vascular permeability by store-operated $\mathrm{Ca}^{2+}$ entry. Am J Physiol 276: L41-50.

Chiono M, Mahey R, Tate G, Cooper DM (1995) Capacitative $\mathrm{Ca}^{2+}$ entry exclusively inhibits cAMP synthesis in $\mathrm{C} 6-2 \mathrm{~B}$ glioma cells. Evidence that physiologically evoked $\mathrm{Ca}^{2+}$ entry regulates $\mathrm{Ca}^{2+}$-inhibitable adenylyl cyclase in non-excitable cells. J Biol Chem 270: 11491155.
Cooper DM, Yoshimura M, Zhang Y, Chiono M, Mahey R (1994) Capacitative $\mathrm{Ca}^{2+}$ entry regulates $\mathrm{Ca}^{2+}$-sensitive adenylyl cyclases. Biochem J 297: 437-440.

Delon J, Bercovici N, Raposo G, Liblau R, Trautmann A (1998) Antigen-dependent and -independent $\mathrm{Ca}^{2+}$ responses triggered in T cells by dendritic cells compared with B cells. I Exp Med 188: 1473-1484.

Distelhorst CW, Dubyak G (1998) Role of calcium in glucocorticosteroid-induced apoptosis of thymocytes and lymphoma cells: resurrection of old theories by new findings. Blood 91: 731-734.

Dolmetsch RE, Xu K, Lewis RS (1998) Calcium oscillations increase the efficiency and specificity of gene expression. Nature 392: 933-936.

Donnadieu E, Bismuth G, Trautmann A (1994) Antigen recognition by helper $\mathrm{T}$ cells elicits a sequence of distinct changes of their shape and intracellular calcium. Curr Biol 4: 584-595.

Emptage NJ, Reid CA, Fine A (2001) Calcium stores in hippocampal synaptic boutons mediate short-term plasticity, store-operated $\mathrm{Ca}^{2+}$ entry, and spontaneous transmitter release. Neuron 29: 197-208.

Enfissi A, Prigent S, Colosetti P, Capiod T (2004) The blocking of capacitative calcium entry by 2 -aminoethyl diphenylborate (2-APB) and carboxyamidotriazole (CAI) inhibits proliferation in Hep G2 and Huh-7 human hepatoma cells. Cell Calcium 36: 459-467.

Fagan KA, Graf RA, Tolman S, Schaack J, Cooper DM (2000) Regulation of a $\mathrm{Ca}^{2+}$-sensitive adenylyl cyclase in an excitable cell. Role of voltage-gated versus capacitative $\mathrm{Ca}^{2+}$ entry. J Biol Chem 275: 40187-40194.

Fantozzi I, Zhang S, Platoshyn O, Remillard CV, Cowling RT, Yuan JX (2003) Hypoxia increases AP-1 binding activity by enhancing capacitative $\mathrm{Ca}^{2+}$ entry in human pulmonary artery endothelial cells. Am J Physiol Lung Cell Mol Physiol 285: L1233-1245.

Fasolato C, Nilius B (1998) Store depletion triggers the calcium release-activated calcium current (ICRAC) in macrovascular endothelial cells: a comparison with Jurkat and embryonic kidney cell lines. Pflugers Arch 436: 69-74.

Fixemer T, Wissenbach U, Flockerzi V, Bonkhoff H (2003) Expression of the $\mathrm{Ca}^{2+}$-selective cation channel TRPV6 in human prostate cancer: a novel prognostic marker for tumor progression. Oncogene 22: 7858-7861.

Floto RA, Mahaut-Smith MP, Allen JM, Somasundaram B (1996) Differentiation of the human monocytic cell line U937 results in an upregulation of the calcium releaseactivated current, ICRAC. J Physiol 495: 331-338.

Freichel M, Vennekens R, Olausson J, Hoffmann M, Muller C, Stolz S, Scheunemann J, Weissgerber P, Flockerzi $\mathrm{V}$ (2004) Functional role of TRPC proteins in vivo: lessons from TRPC-deficient mouse models. Biochem Biophys Res Commun 322: 1352-1358.

Gardner JP, Balasubramanyam M, Studzinski GP (1997) Up-regulation of $\mathrm{Ca}^{2+}$ influx mediated by store-operated channels in HL60 cells induced to differentiate by 1 a,25-dihydroxyvitamin D3. J Cell Physiol 172: 284-295.

Gill DL, Waldron RT, Rys-Sikora KE, Ufret-Vincenty CA, Graber MN, Favre CJ, Alfonso A (1996) Calcium pools, calcium entry, and cell growth. Biosci Rep 16: 139-157.

Golovina VA, Platoshyn O, Bailey CL, Wang J, Limsuwan A, Sweeney M, Rubin LJ, Yuan JX (2001) Upregulated TRP and enhanced capacitative $\mathrm{Ca}^{2+}$ entry in human pulmonary artery myocytes during proliferation. $\mathrm{Am} \mathrm{J}$ Physiol Heart Circ Physiol 280: H746-755.

Harteneck C (2003) Proteins modulating TRP channel function. Cell Calcium 33: 303-310. 
He H, Lam M, McCormick TS, Distelhorst CW (1997) Maintenance of calcium homeostasis in the endoplasmic reticulum by Bcl-2. J Cell Biol 138: 1219-1228.

Hopf FW, Reddy P, Hong J, Steinhardt RA (1996) A capacitative calcium current in cultured skeletal muscle cells is mediated by the calcium-specific leak channel and inhibited by dihydropyridine compounds. J Biol Chem 271: 22358-22367.

Hsu S, O'Connell PJ, Klyachko VA, Badminton MN, Thomson AW, Jackson MB, Clapham DE, Ahern GP (2001) Fundamental $\mathrm{Ca}^{2+}$ signaling mechanisms in mouse dendritic cells: CRAC is the major $\mathrm{Ca}^{2+}$ entry pathway. I Immunol 166: 6126-6133.

Ito E, Oka K, Etcheberrigaray R, Nelson TJ, McPhie DL, Tofel-Grehl B, Gibson GE, Alkon DL (1994) Internal $\mathrm{Ca}^{2+}$ mobilization is altered in fibroblasts from patients with Alzheimer disease. Proc Natl Acad Sci USA 91: 534-538.

Jayadev S, Petranka JG, Cheran SK, Biermann JA, Barrett JC, Murphy E (1999) Reduced capacitative calcium entry correlates with vesicle accumulation and apoptosis. J Biol Chem 274: 8261-8268.

Jayaraman T, Marks AR (2000) Calcineurin is downstream of the inositol 1,4,5-trisphosphate receptor in the apoptotic and cell growth pathways. J Biol Chem 275: 64176420.

Kiselyov K, Mignery GA, Zhu MX, Muallem S (1999) The $\mathrm{N}$-terminal domain of the IP3 receptor gates store-operated hTrp3 channels. Mol Cell 4: 423-429.

Kohn EC, Reed E, Sarosy G, Christian M, Link CI, Cole K, Figg WD, Davis PA, Jacob J, Goldspiel B, Liotta LA (1996) Clinical investigation of a cytostatic calcium influx inhibitor in patients with refractory cancers. Cancer Res 56: 569-573.

Korkiamaki T, Yla-Outinen H, Koivunen J, Karvonen SL, Peltonen J (2002) Altered calcium-mediated cell signaling in keratinocytes cultured from patients with neurofibromatosis type 1. Am J Pathol 160: 1981-1990.

Koski GK, Schwartz GN, Weng DE, Czerniecki BJ, Carter C, Gress RE, Cohen PA (1999) Calcium mobilization in human myeloid cells results in acquisition of individual dendritic cell-like characteristics through discrete signaling pathways. J Immunol 163: 82-92.

Kurebayashi N, Ogawa Y (2001) Depletion of $\mathrm{Ca}^{2+}$ in the sarcoplasmic reticulum stimulates $\mathrm{Ca}^{2+}$ entry into mouse skeletal muscle fibres. J Physiol 533: 185-199.

Lam M, Dubyak G, Chen L, Nunez G, Miesfeld RL, Distelhorst CW (1994) Evidence that BCL-2 represses apoptosis by regulating endoplasmic reticulum-associated $\mathrm{Ca}^{2+}$ fluxes. Proc Natl Acad Sci USA 91: 6569-6573.

Lewis RS (2001) Calcium signaling mechanisms in T lymphocytes. Annu Rev Immunol 19: 497-521.

Lockwich TP, Liu X, Singh BB, Jadlowiec J, Weiland S, Ambudkar IS (2000) Assembly of Trp1 in a signaling complex associated with caveolin-scaffolding lipid raft domains. J Biol Chem 275: 11934-11942.

Luckhoff A, Clapham DE (1994) Calcium channels activated by depletion of internal calcium stores in A431 cells. Biophys I 67: 177-182.

Mattson MP, LaFerla FM, Chan SL, Leissring MA, Shepel PN, Geiger JD (2000) Calcium signaling in the ER: its role in neuronal plasticity and neurodegenerative disorders. Trends Neurosci 23: 222-229.

Meldolesi J, Pozzan T (1998) The endoplasmic reticulum $\mathrm{Ca}^{2+}$ store: a view from the lumen. Trends Biochem Sci 23: $10-4$.

Mentaverri R, Kamel S, Brazier M (2003) Involvement of capacitive calcium entry and calcium store refilling in osteoclastic survival and bone resorption process. Cell Calcium 34: 169-175.
Minke B, Cook B (2002) TRP channel proteins and signal transduction. Physiol Rev 82: 429-472.

Missiaen L, Robberecht W, van den Bosch L, Callewaert G, Parys JB, Wuytack F, Raeymaekers L, Nilius B, Eggermont J, De Smedt H (2000) Abnormal intracellular $\mathrm{Ca}^{2+}$ homeostasis and disease. Cell Calcium 28: 1-21.

Ng LC, Gurney AM (2001) Store-operated channels mediate $\mathrm{Ca}^{2+}$ influx and contraction in rat pulmonary artery. Circ Res 89: 923-929.

Nicotera P, Orrenius S (1998) The role of calcium in apoptosis. Cell Calcium 23: 173-180.

Nilius B (2003) From TRPs to SOCs, CCEs, and CRACs: consensus and controversies. Cell Calcium 33: 293-298.

Nilius B (2004) Store-operated $\mathrm{Ca}^{2+}$ entry channels: still elusive! Sci STKE 2004: pe36.

Norwood N, Moore TM, Dean DA, Bhattacharjee R, Li M, Stevens T (2000) Store-operated calcium entry and increased endothelial cell permeability. Am J Physiol Lung Cell Mol Physiol 279: L815-824.

Parekh AB (2000) Calcium signaling and acute pancreatitis: specific response to a promiscuous messenger. Proc Natl Acad Sci USA 97: 12933-12934.

Parekh AB, Penner R (1997) Store depletion and calcium influx. Physiol Rev 77: 901-930.

Parekh AB, Putney JW Jr (2005) Store-operated calcium channels. Physiol Rev 85: 757-810.

Partiseti M, Le Deist F, Hivroz C, Fischer A, Korn H, Choquet D (1994) The calcium current activated by $\mathrm{T}$ cell receptor and store depletion in human lymphocytes is absent in a primary immunodeficiency. J Biol Chem 269: 32327-32335.

Perez CA, Margolskee RF, Kinnamon SC, Ogura T (2003) Making sense with TRP channels: store-operated calcium entry and the ion channel Trpm5 in taste receptor cells. Cell Calcium 33: 541-549.

Pigozzi D, Tombal B, Ducret T, Vacher P, Gailly P (2004) Role of store-dependent influx of $\mathrm{Ca}^{2+}$ and efflux of $\mathrm{K}^{+}$ in apoptosis of CHO cells. Cell Calcium 36: 421-430.

Pinton P, Ferrari D, Magalhaes P, Schulze-Osthoff K, Di Virgilio F, Pozzan T, Rizzuto R (2000) Reduced loading of intracellular $\mathrm{Ca}^{2+}$ stores and downregulation of capacitative $\mathrm{Ca}^{2+}$ influx in Bcl-2-overexpressing cells. J Cell Biol 148: 857-862.

Pletjushkina OJ, Rajfur Z, Pomorski P, Oliver TN, Vasiliev JM, Jacobson KA (2001) Induction of cortical oscillations in spreading cells by depolymerization of microtubules. Cell Motil Cytoskeleton 48: 235-244.

Pomorski P, Watson JM, Haskill S, Jacobson KA (2004) How adhesion, migration, and cytoplasmic calcium transients influence interleukin-1 $\beta$ mRNA stabilization in human monocytes. Cell Motil Cytoskeleton 57: 143-157.

Preston GA, Barrett JC, Biermann JA, Murphy E (1997) Effects of alterations in calcium homeostasis on apoptosis during neoplastic progression. Cancer Res 57: 537542.

Prevarskaya N, Skryma R, Shuba Y (2004) $\mathrm{Ca}^{2+}$ homeostasis in apoptotic resistance of prostate cancer cells. Biochem Biophys Res Commun 322: 1326-35.

Putney JW Jr (1990) Capacitative calcium entry revisited. Cell Calcium 11: 611-624.

Putney JW Jr (2000) Presenilins, Alzheimer's disease, and capacitative calcium entry. Neuron 27: 411-412.

Putney JW Jr (2003) Capacitative calcium entry in the nervous system. Cell Calcium 34: 339-344.

Randriamampita C, Tsien RY (1993) Emptying of intracellular $\mathrm{Ca}^{2+}$ stores releases a novel small messenger that stimulates $\mathrm{Ca}^{2+}$ influx. Nature 364: 809-814.

Raraty M, Ward J, Erdemli G, Vaillant C, Neoptolemos JP, Sutton R, Petersen OH (2000) Calcium-dependent 
enzyme activation and vacuole formation in the apical granular region of pancreatic acinar cells. Proc Natl Acad Sci USA 97: 13126-13131.

Ris L, Dewachter I, Reverse D, Godaux E, Van Leuven F (2003) Capacitative calcium entry induces hippocampal long term potentiation in the absence of presenilin-1. J Biol Chem 278: 44393-44399.

Robinson IM, Cheek TR, Burgoyne RD (1992) $\mathrm{Ca}^{2+}$ influx induced by the $\mathrm{Ca}^{(2+)}$-ATPase inhibitors 2,5-di-(t-butyl)1,4-benzohydroquinone and thapsigargin in bovine adrenal chromaffin cells. Biochem I 288: 457-463.

Roche E, Prentki M (1994) Calcium regulation of immediate-early response genes. Cell Calcium 16: 331-338.

Rohacs T, Bago A, Deak F, Hunyady L, Spat A (1994) Capacitative $\mathrm{Ca}^{2+}$ influx in adrenal glomerulosa cells: possible role in angiotensin II response. Am J Physiol 267: C1246-1252.

Rosado JA, Sage SO (2000) The actin cytoskeleton in storemediated calcium entry. J Physiol 526: 221-229.

Saavedra FR, Redondo PC, Hernandez-Cruz JM, Salido GM, Pariente JA, Rosado JA (2004) Store-operated $\mathrm{Ca}^{2+}$ entry and tyrosine kinase pp60(src) hyperactivity are modulated by hyperglycemia in platelets from patients with non insulin-dependent diabetes mellitus. Arch Biochem Biophys 432: 261-268.

Sabala P, Amler E, Baranska J (1997). Intracellular $\mathrm{Ca}^{2+}$ signals induced by ATP and thapsigargin in glioma C6 cells. Calcium pools sensitive to inositol 1,4,5-trisphosphate and thapsigargin. Neurochem Int 31: 55-64.

Sabala P, Czajkowski R, Przybylek K, Kalita K, Kaczmarek L, Baranska J (2001) Two subtypes of G protein-coupled nucleotide receptors, P2Y(1) and P2Y(2) are involved in calcium signalling in glioma $\mathrm{C} 6$ cells. $\mathrm{Br}$ I Pharmacol 132: 393-402.

Savic N, Sciancalepore M (1998) Intracellular calcium stores modulate miniature GABA-mediated synaptic currents in neonatal rat hippocampal neurons. Eur J Neurosci 10: 3379-3386.

Short AD, Bian J, Ghosh TK, Waldron RT, Rybak SL, Gill DL (1993) Intracellular $\mathrm{Ca}^{2+}$ pool content is linked to control of cell growth. Proc Natl Acad Sci USA 90: 4986-4990.

Smith IF, Boyle JP, Vaughan PF, Pearson HA, Cowburn RF, Peers CS (2002) $\mathrm{Ca}(2+)$ stores and capacitative $\mathrm{Ca}^{2+}$ entry in human neuroblastoma (SH-SY5Y) cells expressing a familial Alzheimer's disease presenilin-1 mutation. Brain Res 949: 105-111.

Suplat D, Targos B, Sabala P, Baranska J, Pomorski P (2004) Differentiation of answer of glioma C6 cells to SERCA pump inhibitors by actin disorganization. Biochem Biophys Res Commun 323: 870-875.

Thastrup O, Dawson AP, Scharff O, Foder B, Cullen PJ, Drobak BK, Bjerrum PJ, Christensen SB, Hanley MR (1989) Thapsigargin, a novel molecular probe for studying intracellular calcium release and storage. Agents Actions 27: 17-23.

Timmerman LA, Clipstone NA, Ho SN, Northrop JP, Crabtree GR (1996) Rapid shuttling of NF-AT in discrimination of $\mathrm{Ca}^{2+}$ signals and immunosuppression. Nature 383: $837-840$

Trepakova ES, Gericke M, Hirakawa Y, Weisbrod RM, Cohen RA, Bolotina VM (2001) Properties of a native cation channel activated by $\mathrm{Ca}^{2+}$ store depletion in vascular smooth muscle cells. J Biol Chem 276: 7782-7790.
Vandebrouck C, Martin D, Colson-Van Schoor M, Debaix H, Gailly P (2002) Involvement of TRPC in the abnormal calcium influx observed in dystrophic ( $\mathrm{mdx}$ ) mouse skeletal muscle fibers. J Cell Biol 158: 1089-1096.

Vanden Abeele F, Skryma R, Shuba Y, Van Coppenolle F, Slomianny C, Roudbaraki M, Mauroy B, Wuytack F, Prevarskaya N (2002) Bcl-2-dependent modulation of $\mathrm{Ca}(2+)$ homeostasis and store-operated channels in prostate cancer cells. Cancer Cell 1: 169-719.

Vanden Abeele F, Roudbaraki M, Shuba Y, Skryma R, Prevarskaya N (2003) Store-operated $\mathrm{Ca}^{2+}$ current in prostate cancer epithelial cells. Role of endogenous $\mathrm{Ca}^{2+}$ transporter type 1. J Biol Chem 278: 15381-15389.

Vanoverberghe K, Vanden Abeele F, Mariot P, Lepage G, Roudbaraki M, Bonnal JL, Mauroy B, Shuba Y, Skryma $\mathrm{R}$, Prevarskaya N (2004) $\mathrm{Ca}^{2+}$ homeostasis and apoptotic resistance of neuroendocrine-differentiated prostate cancer cells. Cell Death Differ 11: 321-330.

Villalobos C, Garcia-Sancho J (1995) Capacitative $\mathrm{Ca}^{2+}$ entry contributes to the $\mathrm{Ca}^{2+}$ influx induced by thyrotropin-releasing hormone (TRH) in GH3 pituitary cells. Pflugers Arch 430: 923-935.

Waldron RT, Short AD, Gill DL (1997) Store-operated Ca ${ }^{2+}$ entry and coupling to $\mathrm{Ca}^{2+}$ pool depletion in thapsigargin-resistant cells. J Biol Chem 272: 6440-6447.

Wang HG, Pathan N, Ethell IM, Krajewski S, Yamaguchi Y, Shibasaki F, McKeon F, Bobo T, Franke TF, Reed JC (1999) $\mathrm{Ca}^{2+}$-induced apoptosis through calcineurin dephosphorylation of BAD. Science 284: 339-343.

Wei H, Wei W, Bredesen DE, Perry DC (1998) Bcl-2 protects against apoptosis in neuronal cell line caused by thapsigargin-induced depletion of intracellular calcium stores. J Neurochem 70: 2305-2314.

Whitaker M, Patel R (1990) Calcium and cell cycle control. Development 108: 525-542.

Wu X, Zagranichnaya TK, Gurda GT, Eves EM, Villereal ML (2004) A TRPC1/TRPC3-mediated increase in storeoperated calcium entry is required for differentiation of H19-7 hippocampal neuronal cells. J Biol Chem 279: 43392-43402.

Wulfing C, Davis MM (1998) A receptor/cytoskeletal movement triggered by costimulation during $\mathrm{T}$ cell activation. Science 282: 2266-2269.

Wyllie AH (1997) Apoptosis: an overview. Br Med Bull 53: 451-465.

$\mathrm{Xu} \mathrm{SZ}$, Beech DJ (2001) TrpC1 is a membrane-spanning subunit of store-operated $\mathrm{Ca}(2+)$ channels in native vascular smooth muscle cells. Circ Res 88: 84-87.

Yoo AS, Cheng I, Chung S, Grenfell TZ, Lee H, PackChung E, Handler M, Shen J, Xia W, Tesco G, Saunders AJ, Ding K, Frosch MP, Tanzi RE, Kim TW (2000) Presenilin-mediated modulation of capacitative calcium entry. Neuron 27: 561-572.

Yu SP, Canzoniero LM, Choi DW (2001) Ion homeostasis and apoptosis. Curr Opin Cell Biol 13: 405-411.

Yu Y, Sweeney M, Zhang S, Platoshyn O, Landsberg J, Rothman A, Yuan JX (2003) PDGF stimulates pulmonary vascular smooth muscle cell proliferation by upregulating TRPC6 expression. Am I Physiol Cell Physiol 284: C316-330.

Zweifach A (2000) Target-cell contact activates a highly selective capacitative calcium entry pathway in cytotoxic T lymphocytes. J Cell Biol 148: 603-614. 